\title{
Investigation on Read Music Present Situation and Analysis of Teaching in Junior High School
}

\author{
Mo Meng \\ Baoding the Third Middle School branch campus, Baoding 071000, \\ China Mmo1215@126.com
}

\begin{abstract}
Keywords: Junior high school music; Read music present situation; Spectrum teaching; Pitch Teaching; Rhythm teaching
\end{abstract}

\begin{abstract}
In order to study the teaching method of reading spectrum in junior high school, the present situation of reading ability of junior middle school students was studied by questionnaire in this paper, and the present situation and existing problems of reading ability of junior high school students were analyzed. Some suggestions are put forward to improve and improve the ability of reading music. Through the teaching of pitch, rhythm, emoticons and playing, the author combines the music teaching materials of junior high school. This paper drawed lessons from the teaching ideas of the Kodayi music teaching method in Hungary and the Orff teaching method in the Federal Republic of Germany, and puts forward some operable teaching suggestions by analyzing the teaching examples. The teaching contents of playing, creating and appreciating should be combined organically to train students to sing the pitch and rhythm of notes.
\end{abstract}

\section{Introduction}

The compulsory education music curriculum standard (2011 edition) also has the explicit request the reading spectrum must and the singing, the performance, the creation, the appreciation and so on teaching content closely unifies, takes the music as the carrier. On the basis of perceptual accumulation and cognition for the students, the teaching of reading music is carried out. The scientific research of reading music is studied most familiar songs or music. Music reading is a necessary way to learn music. The ability of reading music has a direct impact on whether students can learn music independently or not, and whether they can enjoy music smoothly. In our country, the current forms of music score are mainly simple spectrum and staff spectrum, teachers and students use simple spectrum most, so simple spectrum must be mastered. The teaching aim of reading music teaching is to make students understand music and enjoy the joy brought by music more quickly, so that students can improve their musical literacy and musical intelligence. And build a good music thinking mode, let music teaching play an important role in quality education.

Study on the Spectrum Recognition Status in Junior Middle School. The grade one in junior middle school was Chosen to conduct a questionnaire survey. The results of the questionnaire of 558 students showed that all the students had studied the simple music and more or less read the music in the primary school music class. The questionnaire is divided into three categories according to the students' learning of the staff spectrum. $37.6 \%$ students in primary school who had not studied staff music and had not participated in music training outside school; $26.9 \%$ of primary school music students who have learned staff music but have not participated in music training outside school; The number of students who have participated in music training outside school is 35 . $5 \%$.

\section{Basic Information}

The Present Situation of Learning Staff Spectrum in Music Class in Primary School. The results of the investigation on the current situation of learning the spectrum of staff spectrum in primary school music lesson showed that $47.3 \%$ of the primary school music lessons have learned the spectrum of staff spectrum. 52.7\% of the students who have learned the staff of music in primary school 
Investigation on the Current Situation of Participating in the Training Outside School. The students who had participated in the off-campus training accounted for $35.5 \%$ and those who had not participated in the off-campus training accounted for $64.5 \%$. among them, $24.2 \%$ of the students who had participated in the off-campus training had learned keyboard music. Students who have studied Western orchestral music accounted for $27.3 \%$, folk music students accounted for $21.2 \%$, The students who studied vocal music accounted for $9.1 \%$ and percussion music accounted for $6.1 \%$. The proportion of the other categories was $9.1 \%$.

\section{Examination of Knowledge and Skills for Students}

Investigation of Students' Grasp of Racket Number. The students who answered correctly accounted for $44.1 \%$ of the total. Those who did not know the answer accounted for $39.8 \%$. The students who answered wrong accounted for $16.1 \%$. The correct rate of students who had learned music lessons but never attended extracurricular classes was $40.0 \%$. The correct rate of students who have attended extracurricular classes is $63.6 \%$

Survey of Cognition of Phonetic Symbols for Students. Students who answered correctly accounted for $32.3 \%$ of the total. $55.9 \%$ students who did not know the answer. $11.8 \%$ students who answered wrong. The correct rate of students who had learned music lessons but never attended extracurricular classes was $36.0 \%$. The correct rate of students who have attended the class is $54.5 \%$. The correct rate of this question is obviously less than the correct rate which often appears in the song spectrum.

Examination of Repeated Marks for Students. The students who answered correctly accounted for $43.0 \%$ of the total. $51.6 \%$ of the students who did not know the answer. $5.4 \%$ of the students who answered wrong. The correct rate of students who had not studied the staff spectrum and had not attended the extracurricular classes was $14.3 \%$. The correct rate of students who had learned music lessons but never attended extracurricular classes was $84.0 \%$. The correct rate of students who have attended extracurricular classes is $70.0 \%$.

Examination of Understanding of Extended Marks for Students. Students who answered correctly accounted for $18.3 \%$ of the total, those who did not know the answer accounted for $63.4 \%$ and those who answered wrong accounted for $18.3 \%$. The correct rate of students who had not learned the staff spectrum and had not attended the extracurricular classes was $8.6 \%$. The correct rate of students who had learned music lessons but never attended extracurricular classes was $16.0 \%$. The correct rate of students who had attended the class was $30.3 \%$. Extension marks often appeared at the end of the song. Obviously, the correct rate of this question was a little lower.

Test on Students the Knowledge of the Rhythm of the Simple Spectrum. $42.9 \%$ students answered this question correctly. $11.4 \%$ students answered the wrong question. The students who don't know the answer are $45.7 \%$. It seems that students' efficiency in learning simple spectrum is too low.

Test on Students the Knowledge of the Melody of Simple Music. The students who answered correctly accounted for 13.2 percent of the total, those who did not know the answer accounted for $69.5 \%$.The students who answered the wrong answers accounted for $17.3 \%$. This question shows that the students' knowledge of the simple spectrum is very poor. It can be preliminarily inferred that some students have some understanding of the theory of simple spectrum, but the feeling of pitch and melody is not strong, and the inner hearing is not well established.

In summary, through the analysis of the survey results can be seen in the school music class, teachers pay more attention to the popularity of musical knowledge teaching, the number of exercises in class a lot, but the level of the students is not optimistic. The class of music notation is less than half of the classroom teaching, practice staff notation is very few people. Even the students who study musical instruments, they could not all mastered the knowledge points on the spectrum. The correct rate of investigation involved staff knowledge are not up to the $30 \%$ This shows that students should grasp the lack of knowledge on the spectrum, the students' ability to learn music also have to worry about. 


\section{Suggestions for Improving and Improving the Teaching Ability of Spectrum Recognition}

Correct Attitude on Spectrum Teaching. Since the promotion of quality education, the music class has gradually been attached importance to by school leaders. The spectrum recognition teaching is the main content of music class.

According to the analysis of the survey results showed that It is very difficult for students to meet the requirements of the music curriculum standards. Improving the students' ability of reading musical notation becomes the primary task of music teaching in junior high school.

This is necessary, through classroom education, extracurricular games, singing competitions, musical instruments and other forms to stimulate students' enthusiasm for learning music. Identification of spectrogram is a necessary way to learn music. The role of music score in music learning is equivalent to the role of text in books. Students are fully aware of the importance of learning spectrum, from passive learning to active learning, so as to improve the current situation of the teaching of spectrum recognition.

Strengthening Management and Improving the Teaching Level of Teachers. Teachers play a very important role in teaching and learning, In order to improve the teaching ability of spectrum recognition, first of all, teachers' music quality should be improved, and they should set up good teaching ideas and flexible use of foreign excellent education system in the classroom teaching of spectrum recognition. The teachers' music quality will be improved through training during the holiday, participating in academic conferences, teaching observation, preparation methods, and make them have good occupation accomplishment and lofty ideals, and obtaining a wide range of artistic accomplishment. Secondly, the administrative department of education should provide the material conditions for curriculum implementation, increase investment in the underlying hardware, change idea, realize the importance of music education in quality education, and strengthen the management and explore the use of different evaluation methods for teaching evaluation, improve educational administration management level.

Probe into the Teaching Method of Pitch. In order to stimulate students' interest in learning, Colvin's gestures are applied to the teaching of pitch in the Kodayi teaching method. The students' writing methods and gestures of each sound level are accepted very quickly. However, it is difficult to establish an accurate pitch sense. Although students have already learned the simple score for pitch exercises in primary school, they still need teachers to play the piano for the students to sing with the piano. Otherwise, the tone of a scale will be out of tune when it comes to the next few tones. This will increase the difficulty of teaching.

Lesson example: middle school

Teaching process

Review of Seven Basic Levels of Sound Training

Playing the piano leads the students to sing the scale.

Sing a popular children's song.

Sing the score of the children's song. 


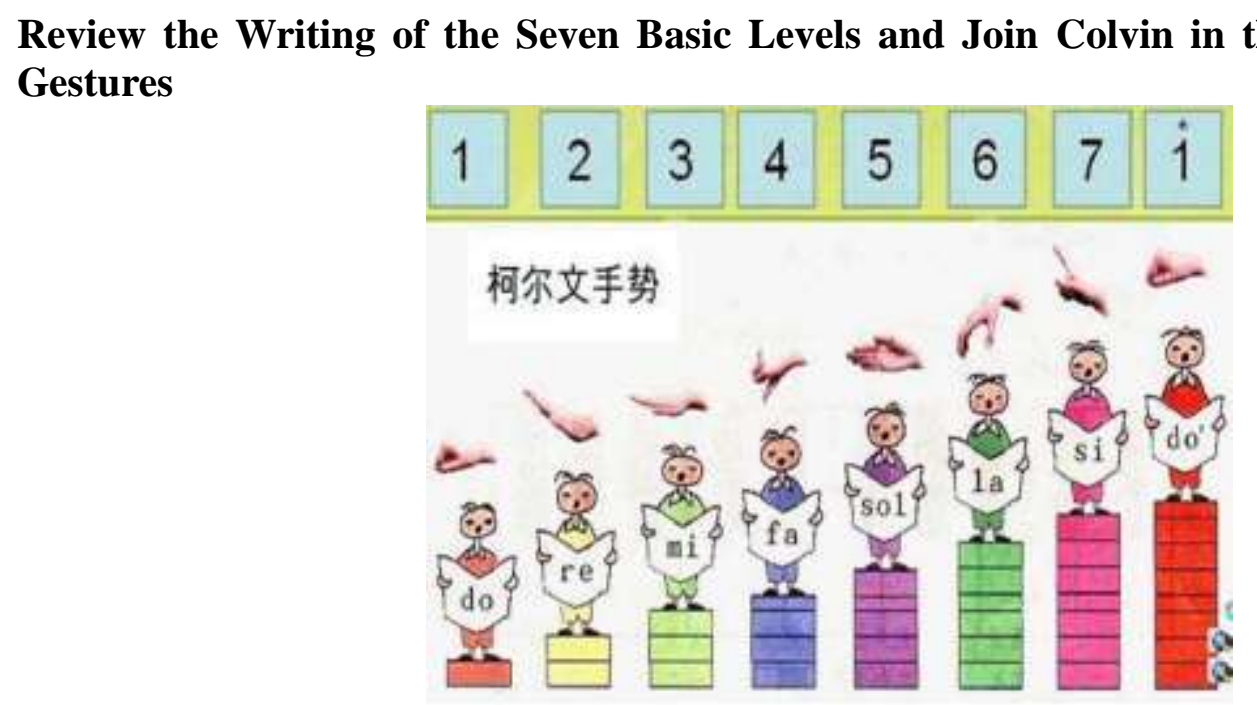

Figure 1.

As shown above, step by step write the letters of the seven basic sound levels and the simplified method, and use the Colvin gesture to sing the students each level

Consolidate Colvin's hand gesture, slow down and sing a short, familiar score, pointing to the pitch on the blackboard, and using the Colvin gesture to sing.

The students were divided into two groups. Two hands command a group of students, using Colvin gestures for dual-part practice.

\section{Learn to Sing "Middle School".}

Listen to songs and feel their musical feelings.

Learn the first part of the song, sing music with the piano, teacher a sentence, students a sentence.

The teacher plays the piano in one hand and uses Colvin's hand gesture in the other.

\section{The Emotional Transfer}

The group sings the feeling song emotion 2

Each sings a motion sentence, the music paragraph completes by the four schoolmates separately, achieves the accurate transmission emotion

\section{Once again Consolidate the Colvin Gesture}

Slowing down and sing the first section of "Middle School" just learned, the seven basic levels corresponding to each sound on the finger blackboard.

Slowing down the score of singing this song, point to the pitch on the blackboard with one hand, and take the students to sing with Colvin's hand gesture.

The first passage of "Middle School" was sung again and the course ended with singing.

\section{Inquiry Teaching Method about Identifying Staff Pitch}

Students have too little contact with the staff spectrum in their study and life, there will be some difficulties in learning it. In the teaching, some students have advocated favouring the simple spectrum, so when teaching the pitch of the staff spectrum, the pitch will be displayed to the students step by step. Let students accept from the shallow to the depth. According to the relationship between the tone pitch teaching, and find some common music elements in student life, music elements can help to improve the learning interest of students. Make them feel close to life, this will stimulate the students' desire to learn.

\section{On the First Tone Singing Method in the Teaching of Literary Records}

According to the order of "sol", "mi", "do", "la", "re", "fa", "xi", seven basic level classes are taught. Make students feel small 3, big 3, simple 5, simple 4, big 6, small 6, simple 8, big 2, small 2, 
increase 4 , reduce 5 interval sensation in turn.

In the teaching method of Kodayi, we start with monosyllabic "sol" and "mi". 3 degrees are downlinked. It was found that the most typical of the musical elements around the students was the sound effect of "Timi beauty" when the game APP king of glory opened, so we started teaching from this sound effect. After the student listening to this sound effect many times, the student is asked, if the first sound is "sol", what is the second sound? After a brief pitch, most students can say "mi", and then write the two notes in a melodic interval to draw the head on the staff spectrum, and ask the students to observe the position relationship between the two sounds. "sol" on any line or room of the staff spectrum. The students are asked to find the location of "mi". Then take the students to sing and use the first tone to sing the fixed pitch on the spectrum. Give examples in different places many times. The students sing the same name each time, but since the pitch position is a fixed pitch on the spectrum, the pitch varies from position to position.

Gradually adding the practice like other pitches. Guiding students to the principle of position relationship between the sound and tone pitch notation to learn for the students. The sol fa foundation staff. Learn to sing sing different with the same fixed pitch roll. The fixed pitch pitch is established for students to learn.

Lesson example: spring River Flower Moon Night

Sound training

Taking the students up and down the scale with Colvin's hand gesture.

Review the pitch learned "sol", "mi", "do", "la"

Specifing any position on the staff spectrum as "mi" and ask the student to write the other three pitches on the spectrum.

The teacher had a pitch with one finger and with one hand he signed Colvin with the other students to sing.

Teaching new pitch "re".

On the basis of the four sounds, the pitch "re" is painted on the basis of a student's singing.

Finger of one hand to pitch, the other hand sets "re" to the other four pitch and sings separately.

Lecturing on Chinese pentatonic scale

Listing the scales on the staff and sing with the students.

Lecturing on Chinese pentatonic scale

Singing the melody of Chinese pentatonic scale, bringing students to experience the charm of Chinese folk music.

\section{Learning music "Spring River Flower Moon Night"}

Listen to the music and be familiar with the melody

After reading the Jane score, the score of the Jianglou Bell Drum in the first section was sung.

In a staff book, the talisman head is drawn all the pitches of this melody with the second line "do".

Following the music, watching the talisman on the staff spectrum is sung this melody

Singing the pentatonic scale again and finishing the class

\section{The Teaching of Reading Spectrum in the Singing Method of Fixed Phonetic Names}

It is helpful for students to improve their sense of music and study mode by mastering the first tone method, but only learning the first tone name method can not help students to establish the concept of fixed pitch, and can not understand the interval and chord more clearly. so we must carry out the teaching of fixed phonetic names.

In the teaching process, if students sing a fixed tone with a ring-name. It is easy to confuse it with the first-tone method, and the method advocated by the Kodayi teaching method has been applied to singing with a fixed phonetic name. The position of pitch on the staff spectrum is corresponding to the position of the keys on the piano keyboard, and the students' sense of fixed sound is established, and the students are taught to play keyboard music easily.

For students, the most frequently encountered number is the treble number. The treble spectrum number, together with the staff spectrum, forms the treble spectrum table, and the second line of the 
treble spectrum table with no tone symbol has a tone of $\mathrm{g} 1$ on the second line. The piano keyboard on the blackboard indicates that $\mathrm{g} 1$, the line of the staff spectrum intersects, each move up a position, on the piano keyboard moves a white key to the right.

When teaching, you can first introduce to the students, but in practice, if one or one of the sounds are spoken to the students in sequence, it will cause students to sing pitch each time there will be a number of sounds. Cannot reflect its phonetic name quickly. Suggests everybody according to the triplet position relations teaching. When carries on the spectrum number teaching, the pitch " $C$ " "F" " $G$ " these three sounds are in the western big tone $14 \quad 4$. The three chords were all big triads. After students were able to match the position of the CFG on the staff spectrum to the position on the keyboard, and to be able to sing with the sound name skillfully. Taking these three notes as the root tone, we build up the big triplet chord, learn the fixed phonetic name step by step according to the order of the sound name that the construction chord comes into contact with, at the same time permeate the concept of the student chord, feel the color of the harmony.

In practice, teaching students to watch the pitch on the five - line spectrum, pop up directly on the piano keyboard. Finding a few simple songs to try playing and sing with fixed - pitch singing and first - tune singing. After the students have mastered, they can learn to know the pitch on the bass and play it on the piano .

\section{Research on Rhythm Teaching Method}

Rhythm is the skeleton of melody. let students first learn some simple rhythm. It is beneficial to the teaching of other knowledge and skills. In rhythm teaching, I combined some of the ideas and methods of Orff teaching. Rhythm recitation, voice activity and multi-part rhythm training are added. In rhythm training, the method of rhythm writing in Kodayi teaching method is used for reference. The junior middle school students have certain logical thinking. And have a unique view of things, Kodak teaching in the rhythm of the method will make students feel too naive, I did not use in the teaching.

\section{Brief Summary}

Music is one of the compulsory courses in compulsory education. It is an important way to improve the quality education in an all-round way. The classroom teaching of music can improve the students' music quality and accomplishment in an all-round way. Reading music score is a necessary tool for students to learn music theory and music skill. Being able to read music can help you understand and enjoy music faster and better in the process of learning music. Improve students' musical literacy and build good musical thinking.

Through the teaching of pitch, rhythm, emoji and playing method, and combined with the junior high school music teaching materials to give operational teaching suggestions. This paper draws lessons from the teaching ideas of Kodayi music teaching method and Orff teaching method, and draws the conclusion that the teaching process must link the teaching content with singing, playing, creating, appreciating and so on. Only in this way can we get good teaching effect and improve students' reading ability.

\section{References}

[1] Dr. John L. Vitale."Let them Jam!" Incorporating Unschooling Pedagogy in the Secondary School Music Classroom[J].Journal of Unschooling and Alternative Learning, 2008, 2 (3), pp. 28

[2] Han Min. The application of interesting teaching in junior high school music teaching [J]. Diary of teenagers (education and Teaching Research), 2015,05:25.

[3] Xiang Yan. The application of project teaching method in music teaching in junior high school [J]. times education, 2013,14:178.

[4] Xue Jiao. The exploration of interactive teaching mode in junior high school music class [J]. 
New curriculum guidance, 2012,34:27.

[5] Guan Ling. Art of classroom regulation in the teaching of music appreciation in senior high school [J]. new curriculum (Part Two), 2016, (7): 64

[6] Feng Tianbo. Problem analysis and optimization of teaching reform in [J].. Drama House, 2015, (05): $179+187$.

[7] He Lili. Classroom control - let the classroom live and not chaos [J]. Gansu education, 2016,0 (A): 55 .

[8] Wei LI.Discussion on Reform of Music Education in Normal Colleges Based on Primary and Secondary School Music Teachers' Quality[J].Higher Education of Social Science, 2015,.8 (5):52-55

[9] KathleenScott Bennetts.Boys' music School context and middle-school boys' musical choices[J].Music Education Research, 2013, 15 (2); 214-230

[10]Jin WANG.Discussion on Primary School Music Teaching: How to Increase Students' Enthusiasm for Learning Music[J].Cross-Cultural Communication, 2015,11 (5):23-26.

[11]Giebelhausen Robin.In the Beginning of the Middle[J].General Music Today, 2015,29 (1): 41-45About Author: Mo Meng,1991.12, Master, Teacher 